\title{
Editorial Comments
}

The pressing need for solid research that informs practice, making of decisions and in the promotion of critical thinking skills for mental health workers, is emphasised in this issue of Health SA Gesondheid. The articles included in this issue address the importance of rigorous research and the application of the findings for all mental health professions.

In the article of Ntsaba and Havenga specific focus was placed on the mental health system in Lesotho, which does not specifically address seclusion of psychiatric in-patients. They suggest guidelines for nurses to deal with the emotional needs of these patients to limit feelings of humiliation and negative emotions.

Du Plessis and Human make a remarkable contribution in their trio of articles about the Delphi technique. In their first article the scientific merit of the Delphi technique is highlighted as a method for decision-making. In the second article the application of the Delphi technique is illustrated to explore a panel of experts' opinions on nurses' health research contribution. Strategies such as building capacity, collaboration, dissemination and the utilisation of research results, amongst others, are made in the third article by Du Plessis and Human, to address the issues that were identified.

In the article of Beuster and Arnott factors contributing to premature termination of treatment for substance addiction, were identified by means of archival data. In the final article Chabeli, strongly opposed to the perception that nurses are assistants of other health professions, suggests that nurses should be critical thinkers that should be manifested in their behaviour and attitude.

\author{
Prof Vera Roos \\ Professional Editor \\ Health SA Gesondheid
}

